\title{
The Ultimate Game Against Nature
}

\author{
Jan-Erik Lane* \\ University of Geneva, Switzerland
}

*Corresponding author: Jan-Erik Lane, University of Geneva, Switzerland.

Received Date: August 20, 2018

Published Date: August 28, 2018

\begin{abstract}
Economist N. Stern has played a majpe in the scientic debate about global warming. Thus, in 2007 he raised correctly the issue about the biggest even externality in the history of human societies. Thaw emission of GHGs were seen by Stern as an example of market failure, having very serious negative effects upon all countries. In 2015, he asked" What are we waiting for?", believing perhaps somewhat naively that external effects could internalized between the countries as easily as externalities are corrected within a county. Policy-making and implementation on climate change is very difficult and complicated, because of the PD at the core of global warming.
\end{abstract}

Keywords: Hot spots; Holoscene; Anthropochene; Game against nature; PD game

\section{Introduction}

The new theory of abrupt climate change, speaking of the risk of tipping points conducive irreversible global warming - a "hotspot Earth", is based on the model of a game against Nature from game theory. The future would hold two states: survival versus extinction for humanity. And two policy responses would cover on the one hand global coordination and country resilience on the other hand. Thus, we have:

The COP21 Treaty is hopefully an example of A, but the probability of success is very uncertain, as B is still possible depending on how COP21 is implemented up to 2030. Countries like for instance the USA may opt for resilience, C, hoping it can develop own measures against the downplayed consequences of global warming. However, the likely outcome of resilience is D, it seems according to several climate and earth scientists.

In the recent inquiry into climate change, "Trajectories of the Earth System in the Anthropocene", published 2018 edited by William C. Clark the transition from the Holoscene to the Anthroposcene period is launched:

"The Anthropocene is a proposed new geological epoch 1based on the observation that human impacts on essential planetary processes have become so profound that they have driven the Earth out of the Holocene epoch in which agriculture, sedentary communities, and eventually, socially and technologically complex human societies developed [1]".
Yet, one could retort that it is now Nature that shrinks the degrees of freedom of men and women, making them victims of Nature's unpredictability and violence. In this perspective, the holoscene period antedating the anthroposcene beginging arund 1700 , lasted for thousands of years. How long will the so-called anthoposcene period last?

The hope among these scholars is also tied to alternative A in Diagram 1. Despite dire warning about the future dismal state of Planet Earth threatening human survival, the authors state that the COP21 promises may save mankind, as long as they restrict global warming to +2 degrees Celsius. I quote:

"This analysis implies that, even if the Paris Accord target of a $1.5^{\circ} \mathrm{C}$ to $2.0{ }^{\circ} \mathrm{C}$ rise in temperature is met, we cannot exclude the risk that a cascade of feedbacks could push the Earth System irreversibly onto a "Hothouse Earth" pathway. The challenge that humanity faces is to create a "Stabilized Earth" pathway that steers the Earth System away from its current trajectory toward the threshold beyond which is Hothouse Earth. The human-created Stabilized Earth pathway leads to a basin of attraction that is not likely to exist in the Earth System's stability landscape without human stewardship to create and maintain it. Creating such a pathway and basin of attraction requires a fundamental change in the role of humans on the planet. This stewardship role requires deliberate and sustained action to become an integral, adaptive 
part of Earth System dynamics, creating feedbacks that keep the system on a Stabilized Earth pathway."

This amounts to wishful thinking. Much more is needed to undo Hawking irreversibility.

\section{The Industrial revolution: progress and energy}

The idea of progress was born with coming of the many innovations during the $18^{\text {th }}$ and 19 th centuries. Perhaps Scottish enlightenment played a crucial role for the thought that human life and the social systems of men and women could be improved year in and year out, endlessly." Paradise" could be accomplished here on Earth promised the new ideologies, replacing religion, when industry and urban dwellings started to replace agriculture and rurality.

The confidence in machines was boundless, as with Karl Marx. Yet, they needed the new form of energy, namely fossil fuels first coal, then oil and finally now massive amounts of natural gas. As the industrial revolution took the form of the adoption of the institutions of modern capitalism, early warnings about tensions between profitability and environmental sustainability were launched, by Marxists and egologists.

Yet, the greenhouse effect from the emission of $\mathrm{CO}_{2} \mathrm{~s}$ was first formulated in a succinct manner by Swedish chemist Arrhenius around 1900, though already French mathematician Fourier anticipated the insight. Not until the 1990 was there a general recognition that fossil fuel consumption would lead to global warming on a scale that threatened humanity.

The insights of people like Keeling, Sawyer, and Hansen inter alia run against mainstream economic theory after 1945, emphasizing the necessity of economic growth for humqn progress. Of particular importance was the notion of "take-off", launched by Rostov in 1960. To raise affluence, countries must experience the time point when capitalist developments take off spontaneously. In Asia, state led measures attempted to simulate the take-off point. National income would start growing in combination with urbanization and industrialization, lifting millions out of poverty. Global economic growth would provide all nations in the market economy with a decent level of human development, or a set of human capacities. The so-called Washington Consensus underlined economic freedom and liberalization of trade and investments. The sooner the take-off, the more likely there would occur catch-up by the Third World. But all of this required one thing, cheap energy.

\section{Affluence and fossil fuels}

The public and private sectors demand lots of energy to produce their goods and services. Energy, or the capacity to do work potentially or actually, is key in economic growth for enterprises and financial institutions in rich countries. And energy is absolutely essential in socio-economic development in poor nations. But energy supply drives the emissions of GHGs, as energy consumption results in GHG emissions as long as fossil fuels dominate supply. Figure 1 shows most recent data about the iron link between GDP, or economic output, and energy consumption, globally.

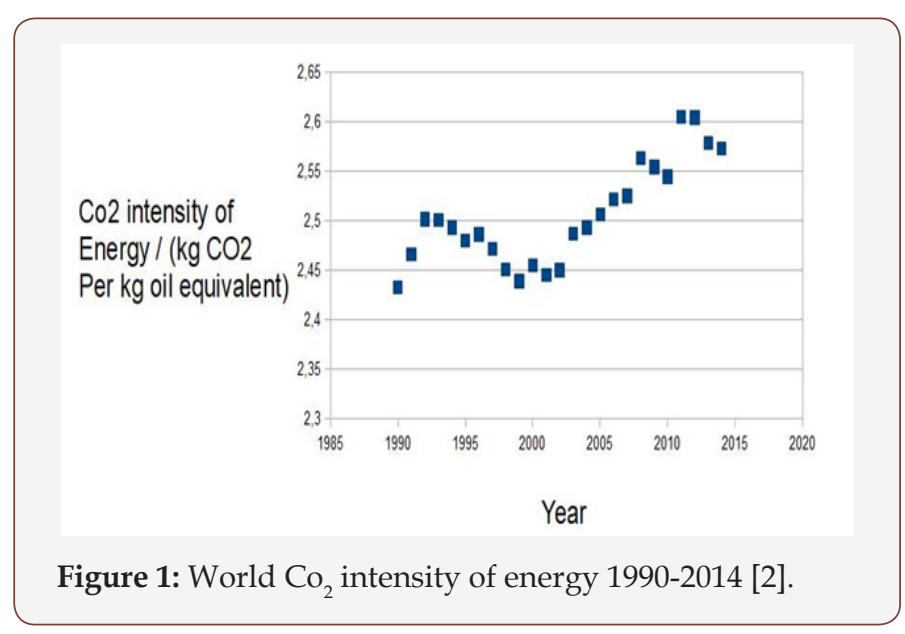

\section{The anthroposcene period: likely end of mankind?}

Scholars now say we face a new period in the history of human beings on Earth, resulting in a quite new climate and ecological degradation. The COP21 Accords were based on a belief that time was available for a slow decarbonisation, managing global warming at around + 2 degrees Celsius, stabilising climate sometimw 2076 the carbon budget approach. These beliefs are now outdated.

\section{Abrupt Climate Change Theory}

Recently launched, climate and earth scientists now focus upon so-called tippng points as well as the great variability in temperature increases over the entire globe. The dramatic changes in the Arctic have made researchers focus upon the melting of the ice at the poles and Greenland and its repurcussions for global weather and the huge methane holdings in the permafrost from Alaska to Siberia, both on land and in ocean.

Tipping point 1: Arctic Sea ice; Expected to disappear around 2020, it will not increase sea levels dramatically due to the eqivalence between ice and water. But this will affect global oceans streams as well as global weather yet streams.

Tipping point 2: Greenland ice; Uncertainty when it will be gone - some say 1940, this will raise sea levels some 6 meters. Major city areas will be inundated: Miami, Rio de Janeiro, Venice, Kairo-Alexandria, Mumbai, Hanoi, Shanghai, Tokyo and Singapore, for instance. It would further deteriorate oceans conveyor belt and the slow the global yet stream.

Tipping point 3: Antartica ice mass; this enormous mass of ice and glaciers would be finished by some 100-500 years, rising sea levels some 60-70 meters. Mankind stand to lose a lot of land all over the planet Earth - a true catastrophe.

Tipping point 4: constant heat increases with draught and potable water scarcity. This would reuce food availability and lead to millions of climate refugees from vunerable low level coastline countries and poor nations along the equator.

Tipping point 5: The methane bomb, or methane emissions from the melting permafrost. This threat is so huge that mankind would never survive such a major release of a very potent GHG. 
The idea of so-called tipping points is that it makes concrete the Hawking notion of irreversibility.

\section{Irreversibility: its Entailment}

When S. Hawking suggested that climate change was irreversible, he was met wih sharp citicism. The notion of an irreversible process of change comes from the theory of scientific laws of nature with their universality and empirical necessity. If global warmin is unstoppable or inevitable, then the survival of the human race is at stake.

The only way to reduce the speed of climate change, avoiding inevitability, is to stop pumping GHGs into the atmosphere. This requires inter alia:

a. immediate stop to coal and charcoal in poor countries;

b. replacing fossil fuel enegy with solar panel parks of the Morroccan Quarzazate kind;

c. initiate now large-scale geo-engineering experiments to suck up $\mathrm{CO}_{2}$ or sequestrate $\mathrm{CO}_{2}$.

Will these measures be taken by the UNFCCC or the G20 group of nations? Probably not. Why? Becaause of the ocean PD game involved. What matters to all countries and governments is access to energy, the culprint of the anthroposcene period.

Hawking irreversibility is practically sure, as massive decarbonisation is highly improbable.

\section{Energy, afflunce and ghg emissions}

Figure 2 shows the tight relation between affluence and energy consumption.

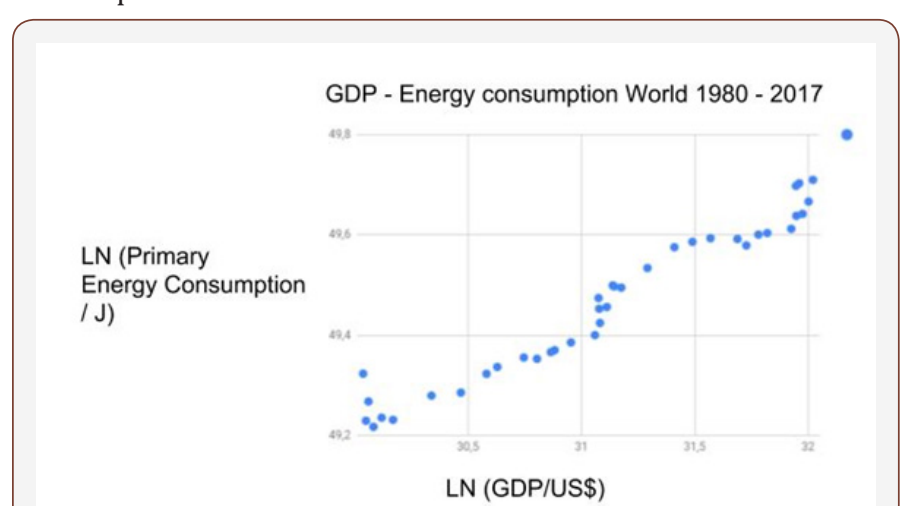

Note: $\mathrm{R} 2=0.951$

Figure 2: Affuence and energy globally [3].

Poor countries need much more energy, but of a new kind. They need assistance to move to modern renewables, as they will give up fossil fuel and charcoal, only if there is compensation by other new energy sources. The enormous demand for more and more of energy comes with a major drawback, namely the GHG emissions. Figure 3 has the picture for the carbon intensity of energy, resulting in $\mathrm{CO}_{2} \mathrm{~s}$.

Very few countrie score under 50 pr cent: Norway and Sweden as well as Switzerland, but several countries score $100 \%$ or close: The Gulf States, Algeria, South Africa, former Soviet Union states (" stans'), Turkey, Mexico, etc.

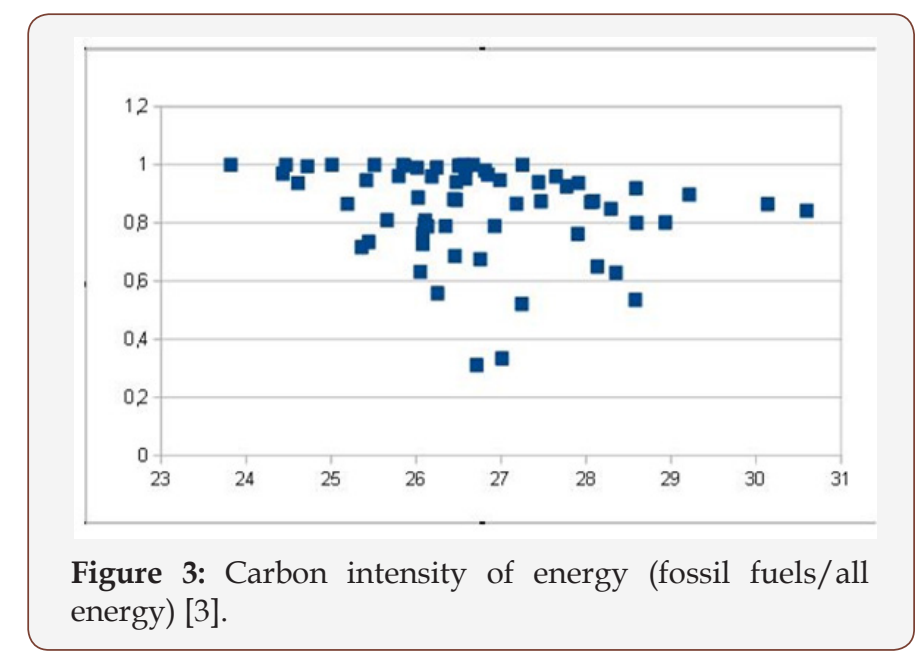

Low energy use leads to poverty, malnutrition, deceases, lack of potable water, insufficient sanitation, etc. Typical of many Latin American, African and Asian nations is the lack of stable electricity, which hampers everything and reduces environmental viability. Figure 4 has the global picture.

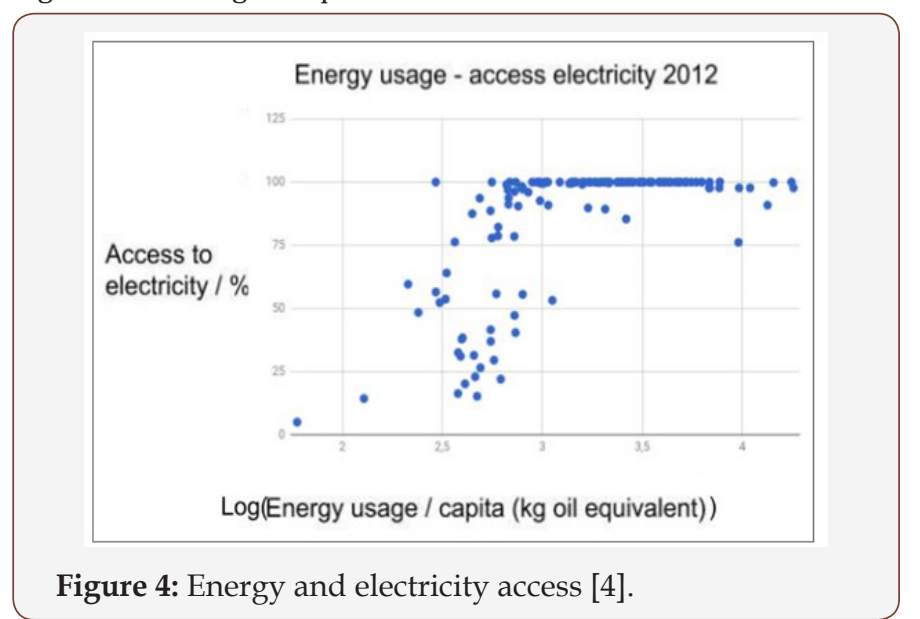

The access to safe and stable electricity is crucial for health, schools, food, water, etc.

The central position of economic growth in rich countries and of socio-economic development in poor countries is much in consonance with basic human drives as well as with the logic of vibrant capitalism in the global market economy. Governments and politicians cherish economic growth, because it makes more policymaking possible.

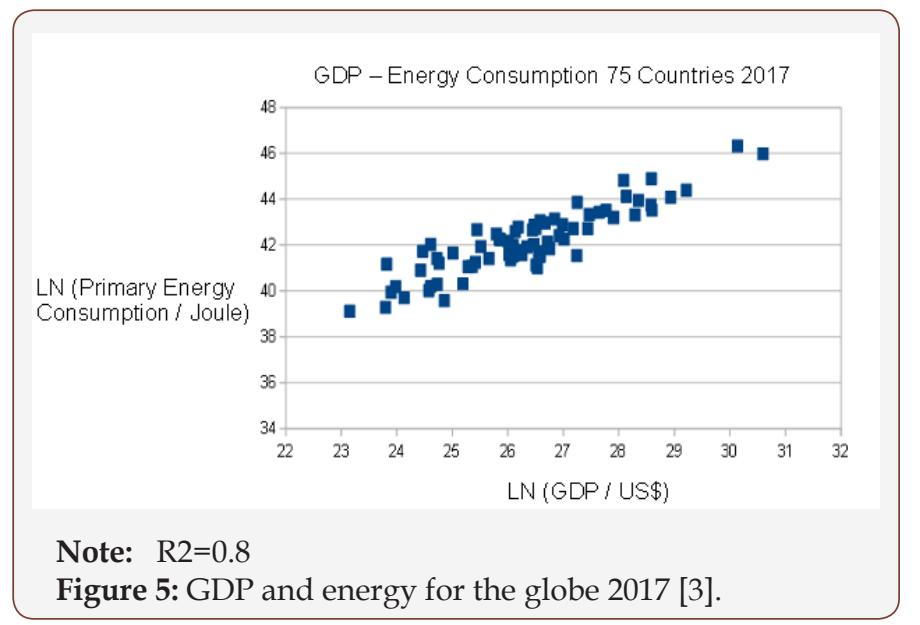


The living conditions in the poor countries in Latin America, Africa and Asia as well as the Pacific reflect the low level of energy employed. This basic fact determines life opportunities in a most dramatic fashion. The low access to energy has consequences for the environment and the life situation of people, including health, schooling, work, food and potable water. Energy is the capacity to do work, which is the foundation of affluence. Figure 5 brings this fact out clearly for 2017.

\section{From progress to retrogression}

With the developments linked to abrupt climate change, the history of mankind will sooner or later take a radical turn, from the spirit of progress since the industrial revolution to a realization of imminent slow decay during the 21st century. The question that humanity faces is nothing less than survival, as Planet Earth moves to the stage of so-called Hawking irreversibility.

The notion of irreversible climate change is somewhat ambiguous. It may denote an absolute unstoppable ending in in Planet Earth being flooded with come 70 meters of water from Antarctica and Greenland at the same as heat soars to a level that humans can badly support. Or Hawking irreversibility entails that unless policies are undertaken to halt the greenhouse effect, global warming could become unstoppable.

Table 1: Number of Ouarzazate plants for 40 per cent reduction of $\mathrm{CO}_{2}$ in some giant countries (Note: Average of 250 - 300 days of sunshine used for all entries except Australia, Indonesia, and Mexico, where 300 - 350 was used).

\begin{tabular}{|c|c|c|c|}
\hline Nation & $\begin{array}{c}\mathbf{C O}_{2} \text { Reduction Pledge/\% of 2005 } \\
\text { Emissions }\end{array}$ & $\begin{array}{c}\text { Number of Gigantic Solar Plants } \\
\text { Needed (Ouarzazate) }\end{array}$ & $\begin{array}{c}\text { Gigantic Plants Needed for 40 \% } \\
\text { Reduction }\end{array}$ \\
\hline United States & $26-28^{\mathrm{i}}$ & 2100 & 3200 \\
\hline China & none & 0 & 3300 \\
\hline EU28 & $41-42$ & 2300 & 600 \\
\hline India & none $\mathrm{e}^{\mathrm{ii}}$ & 0 & 700 \\
\hline Japan & 26 & 460 & 170 \\
\hline Brazil & 43 & 180 & 170 \\
\hline Indonesia & 29 & 120 & 190 \\
\hline Australia & $26-28$ & 130 & 940 \\
\hline Russia & none & 0 & 450 \\
\hline Germany & $49^{\mathrm{ii}}$ & 550 & 210 \\
\hline France & $37^{\mathrm{v}}$ & 30 & 30 \\
\hline Sweden & $42+$ & N/A & 16000 \\
\hline World & N/A & 220 \\
\hline
\end{tabular}

Note: i) The United States has pulled out of the deal; ii) No absolute target; iii) Pledge is above current level, no reduction; iv) Upper limit dependent on receiving financial support; v) EU joint pledge of $40 \%$ compared to 1990.

The likelihood of a giant energy transformation is though mince, given the power of economic growth, socio-economic development and global rivalries.

\section{References}

1. Steffen W, Rockström J, Richardson K, Lenton TM, Folke C, et al. (2018) Trajectories of the Earth System in the Anthropocene. PNAS 115 (33): 8252-8259.

2. Carbon Dioxide Information Analysis Center, Environmental Sciences Division, Oak Ridge National Laboratory, Tennessee, United States.

3. BP Statistical Review of World Energy, World Bank Data Indicators.

4. Environmental Performance Index, Yale University. IEA Statistics (C) OECD/IEA 2014.
Climate and Earth scientists speak confusingly about either unconditional irreversible climate change or conditional unstoppable global warming. The crucial conditions are manmade, referring to policies that halt the $\mathrm{CO}_{2} \mathrm{~s}$, reverse fossil fuel consumption and start large scale geoengineering. Are such policies likely, in the form of global coordination in governance or as country resilience? [5-10].

\section{Conclusion}

My argument is that proper counter-policies to halt climate change are not likely to be forthcoming in time. Nature will put up more and more constraints upon humans and their social systems in the form of heat, fires, sea level rise, land losses, ocean acidification and loss of oxygen as well as s huge stream of people migrations. There will growing scarcity of food and potable water forcing people to move, pushed also by more and more severe land losses. Finally, total economic output or global affluence will start to decline.

What is necessary is global coordination eliminating coal and charcoal, replacing oil and natural gas with solar power parks as well as starting geo-engineering. The need for solar power is colossal (Table 1). 